\title{
Theoretic interpretation of the effect produced by a thin layer of oil spread out at the surface of the sea to calm the agitation of the waves
}

\section{M van der Mensbrugghe}

To cite this article: $M$ van der Mensbrugghe (1883) Theoretic interpretation of the effect produced by a thin layer of oil spread out at the surface of the sea to calm the agitation of the waves, Philosophical Magazine, 15:91, 68-70, DOI: 10.1080/14786448308627311

To link to this article: http://dx.doi.org/10.1080/14786448308627311

Published online: 28 Apr 2009.

Submit your article to this journal ¿

山 Article views: 3

Q View related articles ¿ 
it is sufficient to heat it to the highest temperature of the experiments during a very long time relatively to the duration of the subsequent experiments.

Thus a thermometer which indicates the temperature of the atmosphere, and from time to time is raised to $100^{\circ}$ in order to fix the value of the degree, is prepared for that use by three or four days' heating to $100^{\circ}$. If, however, it is to serve for prolonged experiments at temperatures near $100^{\circ}$, the whole length of it must be heated to $100^{\circ}$ for three or four weeks before graduation and calibration.

If a new thermometer is examined during this treatment, the value of a degree is seen to change in the proportion of about $1: 1.0004$; and with the fixity of the zero towards the end of the heating, the value of the degree is observed to have also itself become fixed ; and it remains constant if the thermometer is left at the ordinary temperature before a fresh determination of the interval from $100^{\circ}$ to zero*.

I agree with M. Pernet in admitting that the value of the degree does not change in ordinary observations, when there is no perceptible change in the position of the zero; but a new thermometer cannot undergo a great number of operations at $100^{\circ}$ without one or other of its constants varying. Thanks to the kindness of $\mathrm{M}$. Mascart, I have been able to submit to a long heating to $100^{\circ} \mathrm{a}$ thermometer which had been in use during more than ten years; and with that instrument no notable change was seen to be produced in the position of the zero. The treatment at $100^{\circ}$ does nothing but imitate the effect of long use. The time necessary for the -treatment is abridged by heating for twenty-four hours in boiling essence of turpentine, and afterwards from four days to a week to $100^{\circ}$; and an analogous procedure serves for higher temperatures.

The glass must not be exposed to the corrosive action of boiling water; and metallic apparatus of easy construction permits those operations to be effected without escape and without contact of vapours of either water or mercury.-Comptes Rendus de l'Académie des Sciences, Nov. 13, 1882, t. xev. pp. 910-912.

THEORETIC INTERPRETATION OF THE EFFECT PRODUCED BY A THIN LAYER OF OIL SPREAD OUT AT THE SURFACE OF THE SEA TO CALM THE AGITATION OF THE WAVES. BY M. VAN DER MENSBRUGGHE.

Since the remarkable experiments of Mr. Shields in Scotland, public attention has been called to the marvellous efficacy possessed by oil for calming the surges of the sea. I have the honour of

* It is to be noted that the thing required is to compare zeros depressed to the maximum, and that the depression does not attain its limit at $100^{\circ}$ until after an hour or an hour and a half. The time necessary to complete the depression diminishes with the elevation of the temperature. 
addressing to the Academy a summary of the propositions with the aid of which I believed I could explain, at the Angust meeting of the Royal Academy of Belgium, how a small quantity of oil spread out upon a large surface can overcome an enormous quantity of vis viva of the waters*.

1. The quantity of work necessary for increasing by 1 square metre the free surface of a mass of water is about 0.0075 kilogramme-metre; this work is stored up, in the form of potential energy, in the fresh surface layer of the water; the thickness of the layer in which that energy resides does not reach $\frac{1}{20} 000$ millim.

2. Reciprocally, if the free surface of the water rapidly diminishes, to each square metre of surface lost an energy of motion equivalent to 0.0075 kilogramme-metre corresponds.

3. Let us in thought isolate a mass of water having a base of 1 square metre and a thickness of 1 metre, and imagine that a mechanical action, such as the wind, rapidly rolls up a superficial layer of 1 square metre base and $\frac{1}{2} 0000$ millim. thickness, laying bare a fresh layer of the same extent; then the potential energy of the first layer will be entirely transformed into energy of motion. If all the layers in succession, each $\frac{1}{20000}$ millim. in thickness, are likewise rolled up, the application of the principle of vires vive shows that theoretically the cubic metre of water can store up 150,000 kilogramme-metres of work, capable of impressing on the total mass a velocity of $54 \cdot 2$ metres.

4. If a superficial layer of water of 1 square metre surface is caused by the action of the wind to slide over the next layer, of the same extent, the latter, being covered by the former, loses its potential energy, but acquires an equivalent quantity of energy of motion; if the action of the wind makes a fresh layer slide over the first two, there is again developed a vis viva equivalent to the lost potential energy of the free surface, and so on.

5. Let us now suppose that a layer of pure water slides over a layer next to it, covered with oil ; from that time the potential energy $(0.0055$ kilog.-m.) of the water covered by a thin greasy layer is replaced by the potential energy of the free surface of pure water $(0.0075$ kilog.-m. $)$, an energy augmented by those of the two surfaces of contact of the submerged thin layer of oil with the water below and the water above: the value of each of these latter is, according to M. Quincke's measurements, 0.002 kilog. $-\mathrm{m}$. Therefore the sliding of the layer of pure water over the oily layer has produced a gain of potential energy of 0.006 kilog.-m. per square metre. But to such a development of potential energy

* It is highly desirable that trials should be made at the mouth of the Seine for the purpose of ascertaining if a relatively minute quantity of oil can, as the facts already known and my theory of the potential energy of liquid surfaces would lead us to presume, prevent the disastrous effects of the violent eddy of the tide. In case of success the employment of oil during storms in harbours, in the vicinity of lighthouses, at dangerous parts of the coasts, \&c. would become a duty. 
an equivalent loss of vis viva necessarily corresponds; and that is the reason why the waves must quickly lose their force as soon as they come into contact with an oily layer.

Such are the very simple propositions which permit me to account for a phenomenon known from ancient times, but which, even on account of its singularity, has not yet obtained the valuable applications it deserves.-Comptes Rendus de l'Académie des Sciences, Nov. 27, 1882, t. xcv. pp. 1055, 1056.

\section{ON THE ELECTRIFICATION OF THE AIR. BY M. MASCART.}

At one of the meetings of the International Committee for the determination of the electric units, lately assembled at Paris, Sir W. Thomson pointed out the importance to science of continuous observations of the proper electrification of the lower strata of the atmosphere by determining the potential in a limited volume of gas taken from the surrounding air and withdrawn from the action of foreign electrical masses.

I have essayed to see by experiment how a mass of air thus isolated preserves its electrification, in order to define the conditions under which it would be expedient to place one's self for the purpose of continuous observation.

The air of the amphitheatre of the Collége de France, which represents, roughly, a cube of 9 or 10 metres side, was electrified by discharging into it a Leyden jar during 10 seconds by a conducting flame. An electrometer, placed in the room, was in communication with a receiving flame placed about 8 metres from the spot where the discharge took place, and 1.5 metre from the ground. As soon as the discharge is commenced the electrometer is affected: the deflection at first undergoes a series of oscillations of great amplitude, then increases in a more regular manner, reaches a maximum at the end of from 10 to 15 minutes, and afterwards decreases very slowly.

The larger oscillations at the outset appeared to result from a direct action of the elcctrified strata of air upon the conducting wires of the electrometer, which were too near them. To eliminate this cause of error, the electrometer was placed in an adjacent room, the communication with the receiving flame being established by a wire passing through the parti ion. In this case the effects are more regular : the maximum deflection was again reached in about a quarter of an hour; it then diminished slowly, obeying a law clearly indicated by the form of the curve to be an exponential, like that for thermal radiation. After two hours the potential was still $\frac{1}{2} \frac{1}{2}$ of its maximum value. Nevertheless there was still manifested, especially during the first minutes, a series of oscillations of small amplitude; and those oscillations were exaggerated as soon as a door was opened even for a very short time, or if an observer crossed the room at several metres distance from the receiving flame.

These phenomena can be naturally explained if it be admitted 